\title{
Exploring the Direction of Curriculum Reconceptualization after COVID-19
}

\author{
코로나 19 이후 교육과정 재개념화 방향 탐색 \\ Ok Han Yoon ${ }^{1}$ \\ 윤옥한 1 \\ ${ }^{1}$ Associate Professor, Department of Education, Kookmin University, South Korea, \\ okaiyoon@kookmin.ac.kr
}

\begin{abstract}
The purpose of this study is to suggest the future of education by exploring the direction of curriculum reconceptualization after COVID-19. The research method is literature synthesis. The review of the research literature resulted in the following findings. First, the reconceptualization of educational objectives must educate a new value chain. Education on a new value chain is needed to create a better order to replace the previous status quo of modern society. Second, the reconceptualization of the curriculum requires the formation and implementation of a convergence curriculum in order to foster creative convergence-type abilities adept for future society. Third, the reconceptualization of educational methods must realize various educational methods suitable for the changed learning tendencies of the digital generation.Fourth, for the reconceptualization of education methods, process-based paper-andpencil evaluations and process-oriented performance evaluations should be balanced. In addition, absolute evaluation rather than relative evaluation is required. It is difficult to reconceptualize the formal decision process in the school field, but it is possible to reconceptualize the performance process. In this respect, it is believed that it will be helpful to nurture talented individuals suitable for future society if teachers are interested in even a partial reconceptualization of the curriculum.
\end{abstract}

Keywords: Curriculum Reconceptualization, Curriculum, Educational Purpose, Educational Method, Teaching and Learning Process, Educational Evaluation

요약: 이 연구의 목적은 코로나 19 이후 교육과정 재개념화 방향을 탐색하여 미래 교육의 방향을 제시하는 것이다. 연구방법은 문헌연구이다. 연구결과는 다음과 같다. 첫째, 교육목적 재개념화는 새로운 가치사슬을 교육해야 한다. 지금까지 현대 사회를 유지해 온 질서 대신 새로운 질서를 창출하기 위한 새로운 가치사슬에 대한 교육이 필요하다. 둘째, 교육과정 재개념화는 미래 사회에 적합한 창의 융합형 인재육성을 위해서는 융복합 교육과정 구성 및 운영이 필요하다. 셋째, 교육방법 재개념화는 디지털 세대의 변화된 학습 성향에 맞는 다양한 교육방법을 실현해야 한다. 넷째, 교육평가 재개념화는 과정중심 지필평가와 과정중심 수행평가가 균형 있게 이루어져야 한다. 또한 상대평가보다는 절대평가가 필요하다. 학교 현장에서는 공식적 결정 과정을 재개념화하는 것은 어렵다 그러나 수행과정에 대한 재개념화는 가능하다. 이러한 측면에서 일부만이라도 교사가 교육과정을 재개념화하는 것에 관심을 갖고 노력할 경우 미래 사회에 적합한 인재양성에 도움이 될 것이라고 판단된다.

Received: August 01, 2021; $1^{\text {st }}$ Review Result: September 20, 2021; $2^{\text {nd }}$ Review Result: November 10, 2021 Accepted: December 31, 2021 
핵심어: 교육과정 재개념화, 교육과정, 교육목적, 교육방법, 교수학습과정, 교육평가

\section{1. 서론}

급격한 과학기술의 발전은 4차 산업혁명을 일으켰다. 이로 인하여 생활의 편리함과 삶의 질이 향상되는 긍정적인 측면도 있지만, 갑작스러운 변화로 인하여 정치, 경제, 사회, 문화, 교육 등 인류의 삶 전반에 큰 혼란이 야기 되고 있다. 4차 산업혁명의 영향력을 교육의 대전환, 교육개혁 패러다임, 미래 교육 등 거대 용어로 포착하는 동시에 교육이 어떠한 구체적인 변화를 해야 하는가? 에 대한 방향을 제시하는 연구들이 많이 등장한다[1-4].

4차 산업혁명 시대에 교육이 어떻게 변화해야 하는가?. 그동안의 모든 기술의 발전이 교육에 영향을 미친 것과 같이 4차 산업혁명도 교육에 큰 영향을 미칠 것이다. 이러한 교육계의 경험은 4차 산업혁명 시대에는 가속화된 속도감으로 교육 전반의 변화 요구에 직면해 있다. 급격한 기술 변화에 더하여 2019년 12월 중국의 후베이성 우한시에서 시작된 신종 바이러스, 코로나19가 발생했다. 이로 인하여 사회의 모습은 기존과는 완전히 다른 형태로 변화하고 있다. 경제적으로는 코로나 19 로 인하여 자본주의의 구조적 공황 현상이 일어나고 있으며, 산업적으로는 외식, 관광, 문화 등의 산업이 급격히 쇠퇴하고 있다.

코로나19 바이러스가 가져온 우리 교육의 새로운 일상은 역기능과 순기능을 동시에 보여주고 있다. 생각보다 먼저 찾아온 미래교육인 비대면 온라인교육은 교사들에게는 수업 콘텐츠의 수동적인 소비자에서 개발자이자 적극적인 활용자로서의 경험을 축적할 수 있는 기회를 제공해주고 있다. 우리 교육이 교실 공간을 벗어나 모든 곳을 수업공간으로 만들 수 있다는 가능성을 실험시켜주고 있다. 학생들은 온라인 수업 공간에서 자신의 주도성을 강화할 수 있는 기회를 경험하고 있다. 그리고 학부모들은 학교 출석과 함께 가정에서 자녀의 공부를 지도하면서 홈스쿨링의 역량을 축적하고 있다.

우리 교육 주체들은 다가온 미래교육을 교육개혁의 견인차로 적극적으로 활용하고 있다. 또한 코로나19 이후 강요된 변화에 노출된 학교는 앞으로 어떠한 역할을 해야 하는지, 그리고 교육의 본질은 무엇인지에 대한 성찰이 필요하다[5][6].

코로나 19 를 대응하는 과정에서 교육은 혁신적 변화의 중심에 서게 되었다. 공교육 기관으로서의 학교가 배움에 있어서 모두가 평등해야 한다는 점, 학생들은 모두 배울 권리가 있다는 기조에 근거하여 보았을 때 현재의 변화 속에서 학교가 공평한 배움을 어떤 방식으로 구현해 낼 것인가에 대한 부분을 고민할 필요가 있다. 강요된 변화 속에서 초래되는 격차와 불평등의 문제, 그에 대한 공교육 기관인 학교의 역할에 대한 논의뿐만 아니라 코로나19가 가져온 변화에 대한 적극적인 대응의 차원을 넘어서 앞으로 교육의 방향이 어떠해야 하며, 교육에서 고민해야 하는 지점이 무엇인지 살펴볼 필요가 있다.

이 연구의 목적은 코로나19 이후 교육과정 재개념화 방향을 탐색하여 미래 교육의 방향을 제시하는 것이다. 연구목적을 달성하기 위한 연구문제는 다음과 같다.

첫째, 코로나19 이후 교육목적은 어떻게야 하는가?

둘째, 코로나19 이후 교육과정은 어떻게야 하는가? 
셋째, 코로나19 이후 교수학습과정은 어떻게야 하는가?

넷째, 코로나19 이후 교육평가는 어떻게야 하는가?

\section{2. 이론적 배경}

재개념론자는 전통적인 교육과정 탐구를 비판적인 시각으로 바라보면서 교육과정에 대한 새로운 견해가 필요하다고 보았다. 교육과정 재개념화 운동에 관한 내용이 끊임없이 진화한다. 교육과정 재개념화 운동은 단일한 시도가 아니다. 거기에는 실존주의, 현상학, 정치학 등 인문학과 사회학에 속하는 거의 모든 시각이 동원되고 있다. 2000년대에 들어 교육과정 연구를 둘러싸고 나타난 사회적·학문적인 변화는 재개념주의 논의에도 변화의 압력을 가하고 있다. 먼저 21 세기의 급격한 사회 변화는 교육과정 분야에서 새롭게 고려해야 할 문제 혹은 기존의 틀이나 관점으로는 해결하기 어려운 복잡한 문제들을 제기하고 있다. 학문적으로는 포스트-모더니즘, 포스트-식민주의, 포스트-휴머니즘 등 새롭게 나타난 사조들이 교육과정 분야에 유입되면서 기존 교육과정 연구의 상태를 재고해 볼 것을 요청하고 있다.

교육과정 재 개념주의가 구체적으로 일어나게 된 것은 1970년대 이후이다. 교육과정 재 개념주의 자들이 처음으로 집단적인 모임을 갖게 된 것은 1973년 파이나(Pinar)의 주도로 뉴욕의 로체스터대학에서 열린 회의이다. 그 이후 1980년대 들어서 교육과정의 이론적 탐구를 다양화하려는 재 개념주의 자들의 노력은 활발해졌으며 1980년 후반에는 그동안 교육과정 이론의 1 세대라고 지칭하던 전통적 '테일러의 논리'는 끝났다고 선언하기에 이르렀다. 파이나(Pinar)는 테일러의 전통적 접근과 달리 교육과정을 보다 철학적이고, 사회-경제적인 맥락에서 새롭게 접근하는 단체들을 교육과정 재개념주의자(reconceptualists)라고 지칭하였다[7]. 그러나 같은 재 개념주의자라고 하더라도 교육과정에 대한 이들의 관심과 접근방식이 모두 같은 것은 아니다. 다양한 학자들이 서로 다른 관점에서 교육과정의 전통적 범주를 넘어 그 탐구 영역을 확장하려고 노력하였다.

재 개념주의의 이론화의 기초는 마르크스주의로부터 실존주의 철학, 현상학, 해석학, 신 마르크스 이론, 정신분석학, 탈현대주의 이론에 이르기까지 복잡한 배경을 갖고 있다. 실존주의와 정신분석학에 바탕을 두고 개인의 교육적 경험 분석과 의미의 추구에 관심을 갖는 파이나와 신 마르크스주의 이론에 바탕을 두고 교육과정의 정치·사회적인 맥락의 분석과 이념의 문제에 초점을 둔 애플은 교육과정을 형식적 교육과정뿐만 아니라 잠재적 교육과정까지 중요한 연구 문제로 다루고 교육과정 재개념화에 관심을 가졌다. 애플의 교육과정에 대한 새로운 개념화 작업은 파이나와 마찬가지로 자신이 하고 있는 일에 대한 깊은 성찰로부터 시작된다. 스스로 교사로서 삶을 되돌아볼 때, 그에게 남은 의문은 학생들의 실패에 대한 책임소재 문제였다. 처음에는 학생들의 책임을 묻기도 하고, 또는 자기 자신이나 교사들의 책임을 따져보기도 하였지만, 결국 이는 그들이 속한 기관이나 사회체제로부터 주어진 인식이나 제도에 더 큰 원인이 있음을 알게 되었다. 애플이 파이나와 다른 점은, 교육 현실의 문제를 인식함에 있어 파이나는 그 관심을 실존적 의식의 세계로 돌려 우리가 갖는 교육경험의 의미와 본질을 파헤치는 일에 초점을 맞추었지만, 애플은 신마르크스주의 이론에 바탕을 두고 그러한 의식을 형성하게 하는 외부적인 조건과 제약이 무엇인지를 따지는 데에 더욱 관심을 두었다.

전통적으로 교육과정학자들은 교육과정을 편성하는 절차를 개발하는 일이다. 그러나 
1950 년대 후반부터 교육과정학자들의 전통적 역할은 도전을 받는다. 그 결과 교육과정학 분야에는 '교육과정의 재개념화' 라 불리는 하나의 운동이 나타나게 된다. 교육과정의 문제를 과거의 학교만의 문제로 간주하기보다는 더 넓은 사회적 맥락에서 찾고자 하였다. 전통적 교육과정은 보비트(Bobbitt)에서부터 테일러(Tyler)에 이르기까지 교육과정의 편성, 절차, 방법, 원리 등의 처방적인 일에 관심을 두었다. 교육과정의 정체성이 실제로는 교육과정 전문가들의 생각보다는 정치, 경제, 사회적 변화에 더 민감하게 반응함을 깨닫지 못하였다. 슈왑(Schwab)의 논문 '타일러 이후의 교육과정학 분야는 죽어가고 있다.'라는 충격적인 선언은 교육과정학의 재개념화라고 하는 새로운 물결을 일으키는 기폭제의 역할을 하였다. 슈왑(Schwab)은 테일러(Tyler)가 취했던 그러한 방향을 추상적인 수준에 머물러 있는 '이론적 탐구'라고 비판하면서 그것에 대한 대안으로서 '실제적 탐구'를 내세우고 있다. 이러한 논문은 당시 교육과정학자들이 동조하면서 1950 1960년대를 지배한 행동주의적이고 기술공학적인 접근에 대한 비판과 함께 새로운 교육과정학의 토대를 구축하기 시작하였다. 이러한 움직임을 교육과정의 ‘재개념화’라고 한다. 맥도날드(Macdonald)는 '교육과정의 재개념화'라는 용어를 처음 사용하였다[8].

교육과정 재 개념주의의 탐구영역은 첫째, 사회.정치적 접근이다. 이 접근에서의 비판은 교육과정의 문제는 결코 학교만의 문제가 아니라는 것이다. 교육과정의 결정은 학교가 속해 있는 사회로부터 영향을 받으며, 정치적인 이해관계에 놓여 있다는 것이며 애플(Apple),만(Mann) 등이 대표적이다. 둘째, 역사적 비판 접근이다. 클리바드(Kliebard)는 전통적인 교육과정 이론이 받아들여 온 가정을 비판적으로 조사하기 위하여 교육과정을 역사적 관점에서 분석하였다. 역사적 비판은 타일러류(탈역사성, 탈사회성)의 교육과정 연구가 현재까지도 가장 지배적인 교육과정 유형으로 자리 잡게 된 배경과 함께 그것의 허점을 들어낸다. 교육과정의 역사적 비판 접근을 이해하기 위해서는 교육과정 자체의 역사뿐 아니라 교육과정과 관련을 맺고 있는 사회구조와 정치 및 경제 구조에 관한 이해가 필요하다. 셋째, 자서전적 접근이다. 파이나의 경우 '코스를 달리다'를 뜻하는 교육과정의 라틴어 어원, ‘쿠레레(currere)'로 대표되는 자서전적 교육과정 이론을 소개하였다. 코스를 달린다는 currere의 의미를 코스를 따라 달리는 개인적 경험을 뜻하는 것으로 이해해야 한다고 보았다. 그는 분배되어야 할 산물로서 교육과정의 개념에서 벗어나 ‘경험하다’라는 쿠레레로 교육과정을 재개념화하고자 하였다. 넷째, 현상학적 접근이다. 현상학적 접근은 학습자 개인의 교육적 경험의 질과 본질에 초점을 맞춘다. 이러한 접근은 즉각적이고 감각적으로 나타나는 경험을 중요시한다. 휴브너(Huebner), 그린(Greene), 맥도널드(Macdonald)등이 대표적이다. 이들은 인간의 지각과 경험, 특별히 인간 경험의 심미적인 질에 초점을 맞춘다[9].

교육과정 재개념화란 교육의 과정(process of education)에 대한 테일러(Tyler)의 모형에 관하여 비판적 검토가 필요한 것을 말한다. 파이나(Pinar)는 이들을 일컬어 전통주의자라고 명명하였다. 테일러(Tyler)의 교육과정 개발 모형은 합리적 모형, 목표 중심모형, 평가 중심모형 등으로 불린다. 테일러(Tyler)는 [교육과정과 수업의 기본원리, 1949]에서 하나의 교육과정 모형으로 체계화하였다. 그의 교육과정 모형은 (1)구체적 목표를 정하고 (2)학습경험을 선정하여 (3)학습경험을 조직하고 (4)마지막으로 평가하는 순으로 모형이 이루어져 있다. 테일러(Tyler) 외에 타바(Taba)는 (1) 목적 및 목표, (2) 내용 및 학습경험, (3) 평가의 3요소로도 제시하였다. 교육과정의 정의에서 학생들이 학습해야 할 모든 경험적인 측면에서 보면 일반적으로 크게 4단계로 구분할 수 있다. 첫째, 
교육목적이나 교육목표 설정, 둘째, 학습경험 선정 및 조직, 셋째, 교수-학습 과정, 넷째, 교육평가이다. 이러한 네 가지 영역은 다시 두 가지 영역으로 구분할 수 있다. 교육목적과 교육 방법이다. 즉, 교육목적을 달성하기 위하여 학습경험을 선정하고 조직할 뿐만 아니라, 실제로 교육목적을 달성하기 위하여 교수-학습 과정이 일어나며, 교육목적 달성을 확인하기 위하여 평가한다.

이상과 같이 교육과정 재개념화는 다양한 관점이 있지만 종합하면 교육과정 재개념화란 첫째, 학습목적이나 학습 목표에 대한 분석이다. 이 목적이나 목표가 왜 선정되었는지 따져 보아야 한다. 둘째, 교육과정 자체가 어떻게 조직되고 구성되었는가에 대한 분석이다. 구체적인 목표에 따라 학습경험 내용이 어떤 기준에 의하여 선정되었는가? 를 비판적으로 분석하고 검토해야 한다. 셋째, 선정된 교육과정 내용이 학교에서 어떤 방식으로 어떻게 전달되고 있는가에 대한 비판적 분석해야 한다. 넷째, 이러한 교육과정이 어떻게 평가되고 있는가 또한 검토되어야 한다는 것이다. 이러한 것을 분석하고 비판하는 것이 교육과정재개념이다.

번스타인은 교육과정 재개념화 관점에서 교육의 자율성을 연구하였다. 테일러의 교육과정 모형 중 (1)교육목표설정 (2)교육내용 선정과 조직은‘공식적 결정 과정'에 속한 것이다. 공식적으로 결정된 교육과정을 실제로는 (3)교수학습과정은 현장에서 어떻게 전달할 것인가? 즉, 어떻게 가르칠 것인가? 와 (4)어떻게 평가할 것인가? 는 ‘수행과정'으로 볼 수 있다. 번스타인이 말하는 교육의 자율성이란 '공식적 결정 과정'과 ‘수행과정'을 구분하는 데서 출발한다. 교육과정사회학에서 중요한 개념중의 하나가 ‘교육과정 개념화'이다. 교육과정개개념화를 두 단계로 구분하면 '공식적 결정 과정과 수행과정에 대한 개념화로 구분한다. 학교 현장에서는 공식적 결정 과정을 재개념화하는 것은 사실상 어렵다. 교육내용 즉 교과서를 다시 만드는 것은 어려운 일이다. 물론 교과 내용을 교사자신이 가르치기 쉬운 방법으로 재구성하는 것은 쉬운 일이지만 주어진 교육내용 자체를 다른 것으로 가르치는 것은 매우 어려운 일이다. 그러나 수행과정에 대한 재맥락화는 쉽게 가능하다. 학교에서 주어진 교육과정을 학교 상황에 맞게 재조절하고 재배열하는 작업이 이루어지는 단계를 말한다. 교육과정 자율성의 근거란 이 두 단계의 불일치 정도를 말한다. 즉, 교사가 수행과정에서 얼마나 자율성을 갖고 수행을 할 수 있느냐에 따라 교육의 자율성이 결정된다는 것이다.

\section{3. 연구방법}

연구방법은 문헌연구와 인터뷰이다. 문헌연구대상은 선행연구, 공청회, 교육부 보도자료, 2015 개정 교육과정, 교육관련 언론 보도 내용 등이다. 문헌연구를 중심으로 교사 10 명을 대상으로 어떤 분야의 재개념화 방향에 관하여 관심이 가장 많은지 포커스 그룹 인터뷰를 실시하였다.

\section{4. 교육과정 재 개념화 방향 탐색}

\section{1 교육목적 재 개념화-바람직한 가치사슬 교육}

교육목적에서 재개념화는 바람직한 가치사슬 교육이다. 바람직한 가치 사슬이란 새로운 가치 체계를 의미한다. 코로나 19 이후 새로운 시대, 새로운 인재상의 필요성이 대두되고 있다. 인간이 왜 무한경쟁을 해야 하는가? 신자유주의로 인하여 야수 
자본주의의 폐해가 민낮을 드러내고 있다. 코로나 19 로 인하여 견고해 보이던 하나의 세계가 변화하고 있다. 신자유주의 시대, 물질주의와 소비주의, 경쟁 지상주의의 세계에 경고등이 켜지고 있다. 포스트 코로나 시대는 거대한 전환의 시대가 될 것이다. 인류가 살아남으려면 모든 것이 변해야 한다. 새로운 가치사슬이란 다음과 같은 것이다. 시장 중심 사회에서 인간중심 사회로, 경쟁 사회에서 연대사회로, 신자유주의 국가에서 복지국가로, 인간의 자연 지배에서 인간과 자연의 공생으로, 능력주의에서 존엄 주의로 전환해야 한다[5][10].

지금까지 세계를 지배하던 체제는 이제는 작동하지 않으리라는 사실이다. 자본주의와 인간에 대한 성찰은 자본주의가 과연 오래갈 체제인지 근본적인 의문을 제기한다. 자본주의는 인간 존엄의 조건인 인간성을 파괴하고, 인간 생존의 조건인 사회를 파괴하며, 인간 생명의 조건인 자연을 파괴하기 때문이다. 이제 ‘자본주의 이후'를 생각할 때다. 포스트 코로나 시대는 질적으로 새로운 체제를 요구하고 있다. 한 사회를 유지하기 위해서는 질서가 필요하다. 현재 세계를 이끄는 질서는 민주주의, 자본주의, 능력주의이다. 이러한 질서도 이제는 다시 점검할 필요가 있다. 새로운 질서를 창출할 필요가 있다. 질서는 하루아침에 형성되는 것은 아니다. 교육에서 끊임없는 가치사슬에 대한 교육을 통하여 새로운 시대에 맞는 새로운 질서를 창조할 필요가 있다[10]. 이러한 측면에서 교육목적 재개념화를 두 가지 제시한다.

첫째, 교육의 양극화 극복이다. 온라인 학습 환경의 차이, 즉 디지털 격차로 인한 교육의 양극화를 심화시키고 있다. 비대면 교육은 경제적, 사회적 취약 계층의 학생, 학습 결핍이 누적된 학생의 학력결핍을 심화시킬 가능성이 높아지고 있다. 온라인 학습을 위한 하드웨어 차이는 물론이고, 온라인 학습에의 경험 정도, 학부모의 자녀 돌봄 정도, 자녀의 학습 습관 등에 따라서 학생들의 학력 차이가 나타나고 있다. 비대면 교육의 현실 속에서도 교육의 양극화가 없는 '균등한 교육'이 가장 중요하다. 기존의 교육격차나 교육 평등에 관한 논의들은 모든 아이에게 동등한 교육의 기회와 조건, 결과를 제공하고, 이를 통해서 취약 계층 아이들의 교육과 삶의 기회를 증진하는 데 초점이 맞추어져 있다. 이는 교육이 사회 분배 정의 실현에 기여한다는 점에서 분명히 의미가 있지만, 기존 사회체제 내에서의 사회 이동이라는 점에서 한계가 있다. 그것은 기존의 불평등한 구조를 변화시키지 못한 채 몇 개의 예외 사례들을 만들어 내 거나 또 다른 승자와 패자를 만들어내는 것에 불과하다. 성, 인종, 계급에 따른 차별, 지배와 특권이 우리 사회에 존속되는 한 교육 불평등은 재생산될 것이고, 개인적인 성공만으로 평등한 사회를 실현하는 데는 명확한 한계가 있다. 이제는 이러한 교육 평등 담론에 대해서 반성해보고, 궁극적으로 교육격차를 해소하고 평등 교육을 실현하기 위해서 교육이 어떤 역할을 해야 하는지에 대해서 고민해 볼 시기가 되었다.

둘째, 사회정의 교육이다. 사회정의 교육은 현재 교육 시스템이 많은 아이들, 특히, 빈곤, 유색인종, 장애 아동에게 적절히 기여하지 못하고 있다는 문제의식에서 출발한다. 사회정의 교육은 넓은 범위의 실천과 관점을 포괄하는 용어이지만, 공통적이고 핵심적인 요소는 학생들이 더 넓은 맥락의 사회 부정의와 불평등을 비판적으로 바라보고, 사회변화를 위해 능동적으로 행동하는 참여 주체가 되어야 한다는 것이다. 사회정의 교육 관점에서 보자면, 동등한 교육의 기회와 불리한 계층 학생들에 대한 보상과 같은 방식으로 교육 평등에 기여하는 것 뿐 아니라 학생들이 사회불평등을 인식하고 적극적으로 변화를 꾀하는 주체가 되도록 교육하여 평등한 사회를 만들어 나가는데 기여하는 것이 궁극적인 교육격차 해소 방안이다. 교사뿐 아니라 사회적으로도 사회정의 
교육에 대한 인식 수준을 향상시킬 필요가 있다. 사회정의 교육이 무엇이고, 그것이 왜 필요한지에 대한 공감대를 형성하고, 교육격차 개선 정책을 보완해 나가야 한다.

학교의 문이 열려 있을 때도 우리는 교육 평등을 지향하지만, 현실은 불평등하였다. 많은 연구는 가정 배경 등의 영향에 따라 발생하는 교육격차의 문제를 지속해서 제기하였다[11-13]. 학생의 가정 배경이 학교 교육에 더 높은 영향력을 발휘하게 될 것으로 예상되는 이 상황에 비추어 교육에서 발생하게 될 격차와 불평등을 조명해야 한다. 지식정보 사회에서의 새로운 지식은 개인 혼자만의 노력으로 만들어지는 것이 아니다. 다른 사람과 더불어 경쟁하고 더불어 교류하는 팀플레이를 통하여 가능하게 된다. 미래사회는 개인의 능력보다 집단지성이 더 요구되는 사회가 될 것이다. 오늘날 사회를 흔히 네트워크 시대라고 한다. 이는 단지 정보통신 분야의 연결망을 의미하는 것이 아니라, 인간과 인간 사이의 네트워크를 의미하는 것이다. 이러한 인간 네트워크 속에서 필요한 것은 정의로운 도덕성과 타인과 더불어 사는 공동체 의식이다. 타인에 대한 배려와 협동이 없는 창의성은 순간적인 재치는 될 수 있을지 모르지만, 진정한 창의성을 갖춘 인재가 될 수는 없다. 이것이 바로 미래사회의 학교 교육에서 새로운 가치사슬에 대한 교육이 더욱 강조되어야 하는 이유이다.

\section{2 교육과정 재개념화-융복합 교육과정 구성 및 운영}

교육과정 재개념화에서 중요한 부분은 융복합 교육과정 구성 및 운영이다. 새로운 가치를 창출하는 학습자는 현재의 상태에 의문을 제기하고, 다른 사람과 협력하며, 새롭게 생각하려고 노력하거나 모순되거나 상충되는 요구들 속에서 조화를 끌어낼 수 있는 능력이 필요하다. 얼핏 모순되거나 상충되는 아이디어, 논리, 입장 간의 상호관련성을 고려하고, 단기적·장기적 시각에서 행동의 영향력을 살필 수 있는 능력이 요구된다. 이런 과정을 통해 학습자들은 반대되는 입장에 대해 더욱 심층적으로 이해하고, 자신의 입장에 대한 논리를 발달시키며, 갈등에 대한 실질적인 해결책을 찾을 수 있다. 행동의 윤리성에 대해 고려하는 능력. 자신의 행동에 대해 자신의 경험, 교육, 그리고 개인적·윤리적·사회적 목표에 비추어 성찰하고 평가할 수 있는 능력이 필요하다.

융·복합교육 과정은 교육과정 편성과 운영 시 교과목 간의 내용 중복을 최소화하며, 창의적 사고, 의사소통, 협업 기능, 책임감 등과 함께 문제해결 능력이 가능하며, 융·복합교육을 통해 학습한 내용을 실생활에서 문제를 해결하는데 적용할 수 있는 능력 등 고차원적 사고능력을 강화한다[14]. 코로나 19 이후 미래 시대의 흐름에 따라 시대에 맞는 인재상으로 문제를 해결하고 문제를 창출해 나가는 융·복합형 인재 양성이 전 세계 교육계의 주요 현안으로 드러나고 있다[15][16]. 21세기 교육 분야에서 가장 큰 이슈 중의 하나는 창의·융합이다. 국가 차원에서도 창의·융합형 인재를 육성하기 위해서 다양한 노력을 하고 있다. 급격한 기술 변화로 융·복합형 인재육성의 필요성이 제기되면서 교육에서도 문제 해결 역량 협력 및 소통 역량이 강조되고 있다.

미래사회가 어떻게 변할 것인가에 대한 예측은 많다. 예를 들면 2030년경에는 무료 인터넷 강좌(MOOCs)와 인공지능(AI) 튜터의 이용이 활발해지면서 대학이 사라지거나 존재 방식이 달라지고, 2025년경이면 인체에 칩(chip)을 넣는 기술이 상용화되어 수백 쪽짜리 교과서를 통째로 인간의 뇌에 업로드 할 수 있는 날이 다가올 것이라는 전망, 또 2030 년경이면 지구상의 기존 직업의 약 $50 \%$ 가 사라질 것이라는 예측 등이 있다. 우리 자녀 세대가 40대가 되었을 때 그들이 학교에서 배운 내용 중 $80 ~ 90 \%$ 는 쓸모없을 확률이 높다. 2030 년의 학교 교육은 크게 두 가지 요인에 의해 크게 영향을 받게 될 
것이다. 하나는 기술과 사회 변화가 미치는 영향이고, 다른 하나는 학교 교육을 바람직한 방향으로 바꾸려는 사회 구성원들의 적극적 의지와 노력이다.

교육과정을 조직할 때 교육과정 구성원리 중 하나인 사회질서의 원리를 반영해야 한다. 이러한 사회 환경변화에 능동적으로 대처해 나가기 위해서는 산업사회에서 만들어진 현재의 교육제도나 교육 시스템으로는 대처하기 어렵다. 지금까지 교육과정을 운영해 왔던 전공과 교과를 철저하게 구분하는 체제가 아니라, 전공과 교과 영역의 경계를 넘나들며 다양한 요소를 반영하여 문제를 해결해 나가는 융·복합 교육이 강조되고 있다[17]. 융·복합교육과정 구성 및 운영이 이러한 시대에서 요구되는 지식의 재창출 능력과 문제해결 능력, 문제창출 능력 함양을 통해 교육경쟁력을 확보하고 융·복합형 인재 육성에 대한 교육적 요구에 부응하는 하나의 방법이 될 수 있다. 융복합형 인재 육성을 위한 학문으로 '융·복합 교육과정 구성 및 운영'을 교육과정 재개념화 방향으로 제안한다.

\section{3 교수학습과정 재개념화-교육방법의 다양화}

기술의 변화가 가져올 가장 큰 변화는 무엇일까? 인간이 하던 많은 일을 인공지능을 갖춘 로봇이 담당하게 된다는 점이다. 기술의 변화는 학교 교육에 긍정적인 영향도 끼칠 것이다. 기술의 사용을 통해 비판적 사고, 창의력 개발 협업과 문제해결을 더 잘 지원할 수 있다. 개별 맞춤학습을 가능하게 하고, 가상현실, 증강현실 등의 활용과 학습게임의 폭넓은 활용은 학습자의 참여와 집중력을 높일 수도 있다. 뇌과학의 발달도 학교 교육 변화에 적지 않은 영향을 끼칠 것이다. 뇌과학의 연구 결과를 교실 수업에 적용할 경우 학습 효율을 지금보다 크게 높일 수 있다. 코로나19 이전으로 돌아갈 수 없다면, 가장 중요한 교수학습 과정 즉 교육 방법에서 재개념화는 교육 방법의 다양화이다.

첫째, 디지털 세대의 변화된 학습 성향에 맞는 교육 방법을 실현해야 한다. 학생들은 교과서보다 이미지·동영상 등 디지털 기반 콘텐츠를 통한 이해를 선호하고, 능동적으로 지식과 정보를 선택하여 학습하는 경향이 있다. 컴퓨터 성능과 메모리 관련 기술이 획기적으로 좋아지고 기계학습 알고리즘과 같은 정보기술이 발전하면서 인공지능은 이제 인간보다도 빠르고 논리적이며 정확해졌다. 가상현실 기술 또한 가상의 현실을 구현하는 기술을 넘어 현실세계를 변형하는 증강현실, 융합현실, 메타버스 등으로 발달하고 있다[18]. 그러므로 원격교육을 활용해 창의적 학습이 가능하도록 미래 교육 생태계를 구축하는 것이다. 학교 내 무선 인터넷 기반 구축과 모든 학생이 본인의 모바일 디바이스를 소유하는 BYOD(Bring Your Own Device)가 기본이다. 이를 바탕으로 교사와 학생이 언제 어디서나 교수와 학습 활동에 활용할 수 있는 지능형 튜터링 시스템을 도입해야 하고, 이를 정부의 플랫폼에서 활용할 수 있도록 해야 한다. 미래 교육에서 에듀테크(Edtech)는 온라인을 기반으로 운영될 것이므로 학생 개인의 관심사와 학습 상황 등에 따라 필요한 콘텐츠를 온라인으로 받을 수 있는 시스템이 필수적이다.

둘째, 혼합형 교육 방법이다. 비대면 온라인교육은 교사들에게는 수업 콘텐츠의 수동적인 소비자에서 개발자이자 적극적인 활용자로서의 경험을 축적할 기회를 제공해주고 있다. 우리 교육이 교실 공간을 벗어나 모든 곳을 수업공간으로 만들 수 있다는 가능성을 실험시켜주고 있다. 다양한 에듀테크를 활용하여 학생들의 수준에 따른 맞춤형 수업 콘텐츠를 제공해야 한다. 그리고 비대면 교육과 대면 교육의 장점을 살린 혼합형 학습(blended learning)을 실행하여 교과 특성에 맞는 수업, 맞춤형 수준별 학습 등을 실현해야 한다. 
셋째, 학생 중심의 개별 맞춤형 교수학습 방법으로 전환되어야 한다.4차 산업혁명 시대 교육은 교수자 중심에서 학생 중심으로, 교수에서 학습으로, 교과과정 중심학습에서 프로젝트 중심 학습으로, 일방적 지식 전수 교육에서 공유와 협력에 기반한 상호학습으로 변화한다. 또한 전통적인 교실을 만남 장소로 변화시킬 것이다. 이 만남의 장소에서 교사는 내용이 어디에 있는지, 어떻게 찾는지, 활용할 수 있는지 등에 대해 안내하는 도서관 사서와 같은 역할을 할 것이다. 공간으로 구분되는 학교가 아닌 '네트워크' 중심의 다양한 교육 체제로 변화될 것이다. 4차 산업혁명 시대의 스마트 기술은 교사는 가르치는 사람, 학생은 배우는 사람이라는 역할에서 변화를 요구하고 있다. 학생은 언제 어디서나 다양한 매체를 통해 배울 수 있는 능동적이고 자율적 존재이다. 교사는 그런 학생의 자율적 능동적 학습을 도와주는 역할을 수행해야 한다. 암기와 계산력에서 배움과 판단이 중요해지는 교육에 맞추어 능력을 개발해야 한다[1-4]. 교사는 학생들을 안내하는 사회적 환경 속에서, 동료와 상호작용하며 다양한 도구를 만들 수 있도록 해야 한다. 학생 중심 수업을 실천하기 위한 다양한 수업 방법 중에서 가장 주목해야 하는 수업 방법은 '프로젝트 학습’이다. 프로젝트 학습은 교사가 과제를 제안하고 교사의 주도하에 단계별로 과제를 해결해나가는, 그리고 결과적으로 과제에 대한 해답이 일정하게 수렴되는 구조화된 프로젝트 학습뿐만 아니라 학생 스스로 프로젝트 학습 과제를 발굴하고, 해결 과정을 계획하고, 해답을 찾는 일련의 과정에서 학생의 자기 주도성이 부각될 수 있는 비구조화, 비정형화된 프로젝트 학습도 포함된다.

\section{4 교육평가 재 개념화-과정중심 평가와 절대평가}

미래 교육평가의 가장 본질적인 기능은 학생의 학업성취 결과를 판단하고 분류하는 것이 아니다. 학생의 학업성취를 촉진하고 보조하는 것이다. 평가는 학습을 위한 학습의 한 과정이지 학습과 독립적인 별도의 활동이 아니다. 미래 사회에서 가장 필요한 역량은 많은 내용적 지식을 기억하고 이해하는 것이 아니다. 그러한 지식을 융합하고 현실에 적용하며 새로운 문제를 해결하고 창출하는 역량이 필요한 것이다. 학교 교육에서 필요한 평가는 내용적 지식을 비판적 사고와 문제 해결, 그리고 분석적 과제에 적용하는 능력을 대상으로 하여야 한다. 내용에 관한 지식뿐만 아니라 그러한 지식을 창의적으로 활용할 수 있는 실천적 수행 능력이 평가의 핵심이 되어야 한다. 이러한 측면에서 교육평가 재개념화 방향은 과정중심 평가와 절대평가 중심이 되어야 한다.

첫째, 학생 중심 수업이 활성화되기 위해서는 과정 중심 평가 이루어야 한다. 총괄식 지필고사, 대입수학능력시험과 같은 결과 중심 평가가 강조된다면 학생 입장에서는 실제 평가를 받게 되는 결과를 준비하기 위한 문제풀이 수업을 원할 수밖에 없다. 교육부 및 시·도교육청의 평가 지침이 철저하고 학생의 대학입시를 고려할 수밖에 없는 현실적 여건으로 인해 과정 중심 평가의 활성화가 제한되고 있다. 과정 중심 지필평가는 지필 방식을 통해 교과 지식을 평가하면서도, 학생 중심 수업의 요체라고 할 수 있는 학습 과정을 놓치지 않을 수 있다는 장점이 있다. 지필 평가의 한계를 극복하기 위해서 과정 중심 수행평가도 함께 이루어 져야 한다. 문제를 해결하는 능력을 함양하기 위해서는 직접 수행하는 것이 필요하다. 프로젝트 학습이 중요한 시대이기 때문에 과정 중심 수행평가도 함께 이루어 져야 한다. 여하튼 과정 중심 평가가 바람직한 평가 방향이다.

둘째, 일반적으로 서열을 기반으로 하는 상대 비교평가 대신 사전에 규정된 준거, 즉 교육목표의 도달 여부를 기준으로 이루어지는 절대기준 평가를 도입해야 한다. 미래사회 인재는 협업하고 소통하며 문제를 해결하고 창출하는 인재가 필요하다. 암기식 지필 
평가와 결과 중심의 상대평가로는 이러한 인재를 육성하는 데 한계가 있기 때문이다.

지금까지 제안한 미래 교육에서의 바람직한 평가의 방향이 그렇게 새로운 것은 아니다. 이미 이론적으로는 위의 내용을 대체로 다 이해하고 수용하고 있다. 다만 교육의 현실에서 그러한 방향으로의 실천이 이루어지고 있지 못할 뿐이다.

코로나 19 이후 교육과정 재개념화 방향에 대하여 교사 10 명을 대상으로 어느 분야에 재개념화가 가장 시급한지 질문한 결과 10 명 중 교육목적이 3 명 $(30 \%)$, 교육과정이 7 명 $(70 \%)$, 교수학습과정이 10 명 $(100 \%)$, 교육평가가 9 명 $(90 \%)$ 으로 나타났다. 결과를 정리하면 [표 1]과 같다.

[표 1] 코로나 19이후 교육과정 재 개념화 방향 인터뷰 결과

[Table 1] Result of Interview on the Direction of Curriculum Reconceptualization After COVID-19

\begin{tabular}{|c|c|c|c|c|}
\hline 구분 & 교육목적 & 교육과정 & 교수학습과정 & 교육평가 \\
\hline $\begin{array}{l}\text { 인터뷰 } \\
\text { 결과 }\end{array}$ & 3명(30\%) & 7명(70\%) & 10명(100\%) & 9명(90\%) \\
\hline 방향 & 가치 사슬 교육 & $\begin{array}{l}\text { 융복합 교육과정 } \\
\text { 구성 및 운영 }\end{array}$ & 교육방법 다양화 & $\begin{array}{c}\text { 과정중심 평가와 } \\
\text { 절대평가 }\end{array}$ \\
\hline $\begin{array}{l}\text { 구체적 } \\
\text { 내용 }\end{array}$ & $\begin{array}{c}\text {-교육양극화 극복 } \\
\text {-사회정의 교육 }\end{array}$ & $\begin{array}{c}\text { - } \\
\text { 융복합교육과정편성 } \\
\text {-사회질서 원리 } \\
\text { 반영 }\end{array}$ & $\begin{array}{c}\text {-디지털 세대의 변화된 } \\
\text { 학습성향에 맞는 교육방법 } \\
\text { 실현 } \\
\text {-혼합형 학습 방법 실현 } \\
\text {-학생 중심의 개별 맞춤형 } \\
\text { 교수학습방법 실현 }\end{array}$ & $\begin{array}{l}\text {-학생 중심 수업 } \\
\text { 활성화를 위한 } \\
\text { 과정중심 평가 실시 } \\
\text {-상대평가 대신 } \\
\text { 절대평가 실시 }\end{array}$ \\
\hline
\end{tabular}

\section{5. 결론}

우리나라 교육계 전반에서 미래 교육에 대한 관심도는 매우 높다. 그러나 급격하게 변화하는 사회적, 문화적 맥락에 부합하면서도 교육 전반에 실질적으로 적용할 수 있는 미래 교육의 구체적인 범위와 수준 그리고 변화 내용은 여전히 모호한 실정이다. 이 연구의 목적은 코로나 19 이후 교육과정 재개념화 방향을 탐색하여 미래 교육의 방향을 제시하는 것이다. 코로나19 바이러스가 가져온 우리 교육의 새로운 일상은 역기능과 순기능을 동시에 보여주고 있다. 미래 교육의 큰 그림은 우리 교육이 걸어갈 나침반의 역할을 하는데 제한적인 의미를 가진다. 결국 미래 교육으로 향하는 중간 지점마다 현실적으로 접목할 수 있도록 하는 안내판이 있어야 한다. 따라서 본 연구와 같이 가까운 미래에 우리 교육이 가야 할 실천 과제를 찾는 일은 매우 중요하며 앞으로 지속해서 이어져야 할 과제이기도 하다.

연구목적에 따른 연구문제는 첫째, 코로나19 이후 교육목적은 어떻게야 하는가? 둘째, 코로나19 이후 교육과정은 어떻게야 하는가? 셋째, 코로나19 이후 교수학습과정은 어떻게야 하는가? 넷째, 코로나19 이후 교육평가는 어떻게야 하는가?이다. 연구문제에 따른 결론은 다음과 같다. 첫째, 교육목적의 재개념화이다. 교육목적 재개념화는 새로운 가치사슬을 교육해야 한다. 우리나라 헌법 제31조 (1)항 "모든 국민은 능력에 따라 균등하게 교육을 받을 권리를 가진다."로 되어 있다. “능력에 따라' 어떤 능력이란 의미인가? 개인의 능력인가? 개인의 경제적 능력인가? 부모의 사회경제적 능력인가? 능력에 따라 균등하게 교육을 받을 권리를 가진다는 의미가 시대정신에 적합한가? 에 
대한 논의가 필요하다고 생각된다. 반대로 해석하면 능력이 없으면 균등하게 교육받을 권리가 없다고 해석할 수 있다. 현대사회를 이끄는 질서 중 능력주의, 더 나아가 신자유주의 정신에 맞춘 법조문이다. 지금까지 현대 사회를 유지해 온 질서 대신 새로운 질서를 창출하기 위한 새로운 가치사슬에 대한 교육이 필요하다. 둘째, 교육 과정 재개념화이다. 교육 과정 재개념화는 융복합 교육과정 구성 및 운영이다. 미래 사회는 초연결사회이며 융복합 사회이다. 이러한 시대에 맞는 융복합형 인재를 육성하기 위해서 교육과정도 융복합형 교육 과정을 구성하고 운영하는 것이 필요하다. 셋째, 교육 방법 재개념화이다. 교육 방법 재개념화는 교육 방법의 다양화이다. 디지털 세대의 변화된 학습 성향에 맞는 교육 방법을 실현해야 하며, 혼합형 학습 방법이 필요하며, 학생 중심의 개별 맞춤형 교수학습 방법으로 전환되어야 한다. 넷째, 교육평가 재개념화이다. 교육평가 재개념화는 과정중심 지필평가와 과정중심 수행평가가 균형 있게 이루어져야 한다. 일반적으로 서열을 기반으로 하는 상대비교평가 대신 사전에 규정된 준거, 즉 교육목표의 도달 여부를 기준으로 이루어지는 절대기준 평가를 도입해야 한다.

어느 분야에서든 변화를 이끌기는 쉽지 않다. 교육과정 재개념화도 마찬가지일 것이다. 학교 현장에서는 공식적 결정 과정을 재개념화하는 것은 어렵다. 그러나 수행과정에 대한 재개념화는 가능하다. 학교에서 주어진 교육 과정을 학교 상황에 맞게 재조절하고 재배열하는 작업이 이루어지는 단계를 말한다. 이러한 측면에서 일부만이라도 교사가 교육 과정을 재개념화하는 것에 관심을 두고 노력할 경우 미래 사회에 적합한 인재양성에 도움이 되리라 판단된다.

\section{References}

[1] Y. J. Jung, N. J. Park, Creative Education and New vision for Future Education in the 4th Industrial Revolution, The Journal of Elementary Education, (2018), Vol, 22, pp.71-76.

[2] J. H. Jeon, A Study on the Future Education Direction of University in the 4th Industrial Revolution : Focusing on the Purpose and Achievements of the Minerva School, Cultural Exchange and Multicultural Education, (2021), Vol.10, No.5, pp.23-58, DOI: https://doi.org/10.30974/kaice.2021.10.5.2

[3] S. S. Cho, The 4th Industrial Revolution and the challenges of future education, Media and Education, (2016), Vol.6, No.2, pp.152-185, https://www.dbpia.co.kr/journal/articleDetail?nodeId=NODE07091942.

[4] K. I. Go, University Education Innovation Cases and Implications for Nurturing Human Resource Suitable for the Needs of the 4th Industrial Revolution, Korean Management Consulting Review, (2021), Vol.21, No.4, pp.461-470.

[5] J. C. Choi, H. J. Jang, J. B. Choi, G. B. Hong, N. R. Kim, K. I. Kim, Corona sapiens: a great transformation of civilization, six representative Korean scholars speak of the future of a new human race, Infuluential, pp.20-38, (2020)

[6] D. H. Lee, Labour law in Crisis in the face of COVID-19 : Suggestions for law reforms for a just and safe workplace, Korean Journal of Law \& Society, (2021), No.66, pp.71-109, DOI: http://dx.doi.org/10.33446/KJLS.66.3

[7] W. Pinar, Curriculum toward new identities, Routledge, pp.36-48, (1998)

[8] J. J.Schwab, The practical 4: Something for curriculum professors to do, Curriculum Inquiry, (1983), Vol.13, No.3, pp.239-265, DOI: https://doi.org/10.2307/1179606

[9] F. P. Hunkins, P. A. Hammill, Beyond Tyler and Taba: Reconceptualizing the curriculum process, Peabody Journal of Education, (1994), Vol.69, No.3, pp.4-18, DOI: https://doi.org/10.1080/01619569409538774

[10] O. H. Yoon, Exploring the Direction of Liberal Arts Education After the Coronavirus Pandemic, Korean Journal of General Education, (2020), Vol.14, No.4, pp.25-34, DOI: https://doi.org/10.46392/kjge.2020.14.4.25 
[11] S. J. Kim, A. N. Kim, J. M. Park, B. J. Lee, W. J. Lee, C. H. Lee, B. K. Joo, S. C. Hong, Distributive Justice and Integration of Korean Society, Yulgok Publishing, pp.230-285, (2018)

[12] S. S. Choi, S. B. Lee, Has Inequality of Educational Opportunity Grown in Korea? : Cohort Trends of Gaps in Educational Attainment by Parental Education over the 20th Century, Korean Journal of Sociology, (2018), Vol.52, No.4, pp.77-113.

[13] B. U. Kim, H. J. Lee, The Critical Review of Equality and Justice in Education, The Research Institue of Korean Education, (2018), Vol.36, No.3, pp.197-219, DOI: 10.22327/kei.2018.36.3.197

[14] J. H. Lee, An Analysis and Improvement Plan of Converged Capstone Design Training for the Promotion of Converged Talent, Journal of the Korean Society of Design Culture, Vol.25, No.4, pp.429-438.

[15] Y. C. L. Richard, Applying online and blended learning structure to teaching practice for STEAM Education, 2020 IEEE Frontiers in Education Conference (FIE), IEEE, pp.1-5, (2020), October 21-24, Uppsala, Sweden, DOI: 10.1109/FIE44824.2020.9274147

[16] J. Jesionkowska, F.Wild, Y. Deval, Active Learning Augmented Reality for STEAM Education-A Case Study, Education Sciences, (2020), Vol.10, No.8, pp.1-15, DOI: https://doi.org/10.3390/educsci10080198

[17] K. I. Joo, A Study on the Acceptance Intention of University Professors on Convergence Education, Korean Comparative Government Review, (2020), Vol.24, No.4, pp.137-166, DOI: 10.18397/kcgr.2020.24.4.137

[18] S. Y. Ko, H. G. Chung, J. I. Kim, Y. T. Shin, A Study on the Typology and Advancement of Cultural Leisure-Based Metaverse, KIPS Transactions on Software and Data Engineering, (2021), Vol.10, No.8, pp.331-338, DOI: https://doi.org/10.3745/KTSDE.2021.10.8.331 